\title{
Clinical Pharmacist Driven Impact towards Intensive Monitoring and Reporting of Adverse Drug Events in Psychiatric Patients
}

Disha A Khoda ${ }^{1 *}$, Madiwalayya S Ganachari', Tarun Wadhwa ${ }^{2}$, Shashikala Walli ${ }^{1}$, Bhupendra Parihar ${ }^{1}$ and Atul Aggarwal ${ }^{1}$

${ }^{1} K L E$ University, Belgaum, Karnataka, India

${ }^{2} R A K$ College of Pharamceutical Sciences, UAE

\begin{abstract}
Background: Drugs are used for the well-being of an individual but apart from its effectiveness many adverse effects are observed. Antipsychotics are the mainstay of treatment for psychotic disorders. Most of the first generation and to a lesser degree second generation antipsychotic agents are associated with ADEs like extra pyramidal symptoms (EPS), sedation and anti-cholinergic side effects.

Method: This study was conducted at a tertiary care hospital. Informed consent was obtained from patients care takers. Patients aged $\geq 18$ years of either gender admitted to psychiatry department were included in the study. Patients on OPD basis, emergency, ICUs and special population were excluded. The main objective of the study was to estimate the incidence of ADEs and evaluate ADEs based on various parameters like demographics, drug class implicated, individual drug implicated, organ system affected, and analysis of ADEs (causality, severity and preventability)

Result: A total of 58 patients were enrolled into the study. Out of them, 32 patients experienced 90 ADEs. The incidence rate was found to be $55.17 \%$. Male $(65.51 \%)$ preponderance was observed over females $(34.48 \%)$. Benzodiazepine was reported to be one of the major drug class implicated in which Lorazepam accounted for $36.51 \%$ ADEs. CNS was one of the most prominent systems affected due to ADEs.

Conclusion: The fact goes undenied, psychiatric patients are prone towards adverse events, the only good that could be done to these subjects is try avoiding and minimizing the events. This could be possible only by thorough monitoring of such cases. Our results showed incidence rate of $79.31 \%$. This incidence rate could be minimized by the presence of a clinical Pharmacist for better treatment and creating awareness of the medicines to the patients.
\end{abstract}

Keywords: Adverse drug events; Antipsychotics; Extra pyramidal side effects; Pharmacovigilance

Abbreviations: ADE: Adverse Drug Event; WHO: World Health Organization; IEC: Institutional Ethics Committee

\section{Introduction}

Drugs are used for the well-being of an individual but apart from its effectiveness many side effects are observed. The Harward Medical Practice Study was one such study which showed that the incidence of iatrogenic injury in hospitals and medicines were the main cause of injury to the patients. In United States approx 98,000 patients per year suffered from medical errors [1]. In Britan, it was seen that more than 10,000 patients per year were dying because of the bad reactions of the drugs [2]. The side effects seen from Drugs and their use are in general termed as 'Adverse drug reactions' (ADRs). World Health Organization (WHO) describes adverse drug reactions as a "Response that is noxious or unintended, and that occurs at doses normally used in humans for the prophylaxis, diagnosis, or therapy of a disease, or for the modification of physiological function" and an 'Adverse Drug Event' (ADE) is defined as "an injury resulting from the use of a drug."

It is well known that $30 \%$ of the documented adverse drug reactions are neuropsychiatric and such drugs can cause depression, insomnia, memory impairment, self-harming, aggression, mania and suicidal ideation. Cessation of drug therapy can abort these symptoms, but they trigger them too [3]. Antipsychotics are the mainstay of treatment for psychotic disorders. Newer atypical antipsychotics and their traditional counter parts are more prone to drug- drug interactions within themselves and other agents used concomitantly in the treatment of various ailments. Most of the first generation and to a lesser degree second generation antipsychotic agents are associated with adverse drug events like extra pyramidal symptoms (EPS), sedation, anticholinergic side effects and various metabolic disorders [4].

Most of the data available on adverse drug events addresses to patients of out setting departments, surgery wards, medicine wards and every few towards psychiatric in-patients; where the patient's life is on continuous alteration of doses and outcome of which at times is seen as an adverse event. A MEDLINE search using the terms adverse drug reactions, hospital, psychiatry in patients showed a great paucity of literature (1950-december 2009) [5].

Psychiatry patients are on a regimen of more than 3 to 4 drugs in their daily routine; with the increasing number of drugs, increases the chances of drug interactions. In general, drug interactions are known to occur with many agents used commonly in conjunction with many antipsychotics such as anti-cholinergic, anti-convulsants, antidepressants, anxiolytics and lithium. Most of the data on anti-psychotic interactions has been extracted from case reports. It is quite difficult to derive inferences from available data due to lack of well documented studies [4].

*Corresponding author: Disha A Khoda, Paddm-Kunj Apartments, 4842A/39A 2nd main 2nd cross, Sadashivnagar, Belgaum, Karnataka, India, Tel: +919916251092; E-mail: dishakhoda@gmail.com

Received March 14, 2014; Accepted March 10, 2014; Published March 17, 2014

Citation: Khoda DA, Ganachari MS, Wadhwa T, Walli S, Parihar B, et al. (2014) Clinical Pharmacist Driven Impact towards Intensive Monitoring and Reporting of Adverse Drug Events in Psychiatric Patients. J Pharmacovigilance 2: 128. doi:10.4172/23296887.1000128

Copyright: @ 2014 Khoda DA, et al. This is an open-access article distributed under the terms of the Creative Commons Attribution License, which permits unrestricted use, distribution, and reproduction in any medium, provided the original author and source are credited. 
Some of the previous studies have suggested an increased occurrence of diabetes and other metabolic disturbances with atypical antipsychotic agents such as clonazepam and olanzapine which are of great concern to psychiatrists. A number of prior studies have also documented abnormal glucose metabolism during treatment with clonazepam, olanzapine, resperidone and quetiapine [4].

The physiologic and psychological conditions of the psychiatric patients are on a continuous change and for the same, drugs and their doses have to be tapered and adjusted accordingly. With frequent tapering of doses increases the chances of non-compliance to patients and may provoke in the form of adverse drug events many times.

Availability of various anti psychotics helps to choose a better drug for patients in case of intolerable side effects as adverse effects could delay the recovery of the individual and on par prolongs the hospital stay [6].

Drug induced adverse events could affect the quality of life of patients especially if they are suffering from psychiatric illness with delusional status. Illusion of disease and intolerability of drugs could be improved upon through vigilant monitoring and applying pharmacist driven scientific tools in healthcare practice. There is a paucity of literatures related to adverse drug events in psychiatric patients as far as Indian scenario is concerned. Therefore, we need to develop a strong pharmacovigilance network in psychiatry department via thorough evaluation of drug use and monitoring, detection, reporting and analysis of ADEs. This study has been undertaken to assess scientific tools vigorously for monitoring, detection, analysis and reporting of ADEs.

\section{Materials and Methods}

\section{Study setting}

KLES Dr. Prabhakar Kore Hospital and Medical Research Centre, Belgaum, Karnataka is a 2200 bedded, multispecialty, tertiary care teaching hospital which is providing healthcare services to patients

\begin{tabular}{|c|c|c|}
\hline \multirow{2}{*}{ Age ( year) } & \multicolumn{2}{|c|}{ Gender } \\
\hline $18-24$ & Male & Female \\
\hline $25-31$ & 5 & 06 \\
\hline $32-38$ & 08 & 04 \\
\hline $39-45$ & 10 & 04 \\
\hline $46-52$ & 7 & 01 \\
\hline $53-59$ & 6 & 03 \\
\hline$\geq 60$ & 00 & 02 \\
\hline Total & 02 & 00 \\
\hline & 38 & 20 \\
\hline
\end{tabular}

Table1: Demographics.

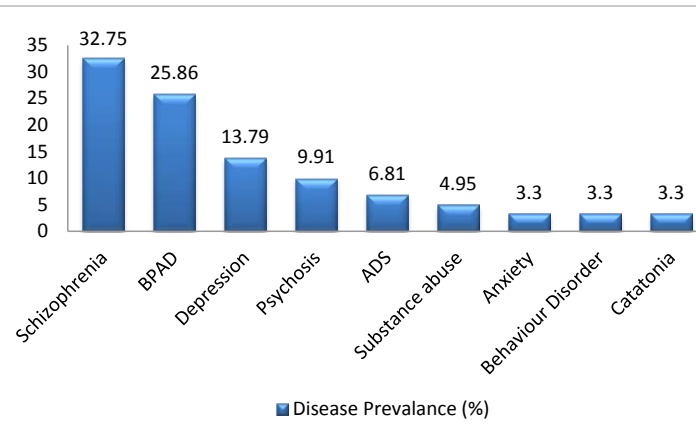

Figure 1: Disease Prevalence. in and around Belgaum district. It is a prospective surveillance and observational study.

\section{Study duration}

Data collected for 3months, analysed in 1month.

\section{Objectives}

The study was designed with a primary objective to study the impact of intensive monitoring, detection, analysis and reporting of adverse drug events in psychiatric patients. And also to evaluate ADEs based on various characteristics like demographics, drug class implicated, organ system affected, predisposing factors, dechallenge, and rechallenge by making use of standardized scales for causality, severity, predictability and preventability.

\section{Methodology}

A prospective intensive monitoring study was carried out to assess, monitor and evaluate the adverse drug events in the hospitalized psychiatric patients for a period of 3 months; in KLE's Dr. Prabhakar Kore Hospital and MRC-Belgaum. Before start of the study Institutional Ethics Committee permission was obtained. Inform consent form was designed in four vernacular languages (English, Hindi, Kannada and Marathi) and administered as per the patient's feasibility. Patient information form was developed and handed to the patients.

A total of 58 patients were screened during the time period. Patients above the age of 18 were screened on daily basis during their hospital stay and were checked for the occurrence of any adverse drug events. The patients were screened from the day of admission till the day of discharge. The details of the patients were noted in a specially designed form taking into account patient's demographics, medical history, medication history, complaints on admission, past allergic reactions, provisional diagnosis, current therapy, drug treatment chart, additional tests conducted, discharge medications and advice. On suspicion of an ADE the case file of the subject was thoroughly evaluated and discussed with the medical staff with the association of drug therapy and onset of ADE.

The adverse drug events were noted in an ADE monitoring and documentation form. The events were further classified using scientific tools like WHO scale, Naranjo scale, Modified Schumock and Thornton scale and Hartwig scale into Casual, Probable, Preventable and Severe $\mathrm{ADE}$. The patients on discharge were checked for any ADE, if so were rechecked by telephonic contact. Patients belonging to gestation, lactation, pediatric group and referred cases were not included for the study.

\section{Result}

A total number of 58 patients were screened during the study period, out of which 32 patients showed adverse drug events. A total of 90 ADEs were reported during the study duration from the hospital psychiatry ward.

A total of 38 males and 20 females accounted for the total patient number. The demographics on comparison showed males (38) got hospitalized on a greater number due to psychiatry disorders on par to females (20) (Table 1).

The incidence rate of ADE in our study was found to be $55.17 \%$. On comparing the clinical diagnosis it was seen that Schizophrenia $(32.75 \%)$ accounted for the highest number of cases, followed by bipolar maniac disorder (25.86\%) and depression (13.79\%) (Figure 1). 
Citation: Khoda DA, Ganachari MS, Wadhwa T, Walli S, Parihar B, et al. (2014) Clinical Pharmacist Driven Impact towards Intensive Monitoring and Reporting of Adverse Drug Events in Psychiatric Patients. J Pharmacovigilance 2: 128. doi:10.4172/2329-6887.1000128

\begin{tabular}{|c|c|}
\hline $\begin{array}{c}\text { Drugs responsible for } \mathbf{9 0} \text { Adverse drug } \\
\text { events noted among } \mathbf{5 8} \text { patients }\end{array}$ & No. ( Percentage of all ADEs) \\
\hline Lorazepam & $28(31.11 \%)$ \\
\hline Olanzapine & $13(14.44 \%)$ \\
\hline Lithium & $11(12.22 \%)$ \\
\hline Resperidone & $06(6.66 \%)$ \\
\hline Clonazepam, carbamazepine, Sertraline & $04(4.44 \%)$ \\
\hline Asenapine, Trifluperazine & $03(3.33 \%)$ \\
\hline Oxazepam, Escitalopam & $02(2.22 \%)$ \\
\hline Trihexyphenidyl, Armodafinil, Clonidine, & $01(1.11 \%)$ \\
\hline
\end{tabular}

Table 2: Individual drugs causing ADEs.

\begin{tabular}{|c|c|}
\hline Type of ADE & $\begin{array}{c}\text { No. ( Percentage of all } \\
\text { ADEs; } \mathbf{n = 9 0} \text { 90 }\end{array}$ \\
\hline Decrease Appetite & $15(16.6)$ \\
\hline Hand tremor & $13(14.4)$ \\
\hline Akathesia & $11(12.2)$ \\
\hline Generalized weakness, Irritability, Headache & $06(6.6)$ \\
\hline Dizziness & $05(5.5)$ \\
\hline Perioral tremors & $04(4.4)$ \\
\hline $\begin{array}{c}\text { Increased Sleep, Giddiness, Nausea and Decrease } \\
\text { Sleep }\end{array}$ & $03(3.3)$ \\
\hline Constipation, Slurred Speech, Body Stiffness, Dry \\
mouth
\end{tabular}

Table 3: Different types of ADEs occurred and the total percentage of ADEs.

\begin{tabular}{|c|c|c|}
\hline Name of Drug & $\begin{array}{l}\text { Organ system } \\
\text { affected }\end{array}$ & Drug class( ATC code) \\
\hline Lorazepam (N05BA06) & Nervous system(N) & $\begin{array}{c}\text { Anxiolytics(n05b) } \\
\text { Benzodiazepine } \\
\text { derivatives(n05ba) }\end{array}$ \\
\hline Olanzapine (N05AH03) & Nervous system(N) & Antipsychotics (n05a) \\
\hline Resperidone (N05AX08) & Nervous system(N) & Antipsychotics (n05a) \\
\hline Clonazepam (N03AE01) & Nervous system(N) & Antiepileptics(n03a) \\
\hline Lithium (N05AN) & Nervous system(N) & Antipsychotics (n05a) \\
\hline Haloperidol (N05AD01) & Nervous system(N) & Antipsychotics (n05a) \\
\hline Sertraline(N06AB06) & Nervous system(N) & Psychoanaleptics (n06) \\
\hline Trifluperazine (N05AB06) & Nervous system(N) & Antipsychotics (n05a) \\
\hline Carbamazepine (N03AF01) & Nervous system(N) & Antiepileptics(n03a) \\
\hline Divaloprex sodium (N03AG01) & Nervous system(N) & Antiepileptics(n03a) \\
\hline Chlorpromazine (N05AA01) & Nervous system(N) & Antipsychotics (n05a) \\
\hline Iloperidone (N05AX14) & Nervous system(N) & $\begin{array}{l}\text { Other antipsychotics } \\
(\text { (n05ax) }\end{array}$ \\
\hline Quetiapine (N05AH04) & Nervous system(N) & Antipsychotics (n05a) \\
\hline Asenapine (N05AH05) & Nervous system(N) & Antipsychotics (n05a) \\
\hline Mirtazapine (N06AX11) & Nervous system(N) & Antidepressants (n06a) \\
\hline Tramadol (N02AX02) & Nervous system(N) & Analgesics (n02) \\
\hline Ethopropazine (N04AA05) & Nervous system(N) & $\begin{array}{l}\text { Anti-Parkinson drugs } \\
\text { (n04) }\end{array}$ \\
\hline Desvenlafaxine (N06AX23) & Nervous system(N) & Antidepressants (n06a) \\
\hline Escitalopam (N06AB10) & Nervous system(N) & $\begin{array}{l}\text { Psychoanaleptics (n06) } \\
\text { Antidepressants (n06a) }\end{array}$ \\
\hline Lamotrigine (N03AX09) & Nervous system(N) & Antiepileptics (n03a) \\
\hline Gabapentin (N03AX12) & Nervous system(N) & Antiepileptics (n03a) \\
\hline Clonidine (C02AC01) & $\begin{array}{l}\text { Cardiovascular } \\
\text { System (C) }\end{array}$ & Antihypertensive (c02) \\
\hline Trihexyphenidyl (N04AA01) & Nervous system(N) & $\begin{array}{l}\text { Anti-Parkinson drugs } \\
\text { (n04) }\end{array}$ \\
\hline
\end{tabular}

Table 4: ATC Classification.

Few groups of patients were on concomitant medications for conditions like diabetes, hypertension, anemia and pain along with antipsychotic therapy. The drug history was noted very carefully for such conditions before attributing them to be a part of adverse events.

The drug that accounted for maximum ADE in our setting included Lorazepam (31.11\%), Olanzapine, Lithium and so on as mentioned in the (Tables 2 and 3); The results of this study showed that benzodiazepines $(46.66 \%)$ were the highest class of drugs to cause adverse drug events followed by atypical antipsychotics (16.6\%), antimaniac (12.2\%), antidepressant (11.1\%) and least being anti-cholinergic, central alpha agonist and antipsychotics (1.11\%) (Table 4 ).

Patients on multiple drug therapy added to the ADEs because of Drug -drug interactions within themselves. Most prominent drug interaction was seen between Lithium+Olanzapine (Table 5).

It was bought into consideration that many patients were deprived of appetite; on clinical correlation it was seen that most of it was due to the disease condition and a few accounted for drugs. Few special cases were seen where in 2 patient's male of 28 and 30 years each experienced burning sensation in stomach after consuming Olanzapine $5 \mathrm{mg}$ for the first time, an antidote was given to overcome it. Weight gain of $2 \mathrm{kgs}$ was seen in a male patient on consuming olanzapine; drug was withdrawn and shifted the therapy to another psychotropic drug. There was one patient who developed hiccups after undergoing his first ECT.

Central nervous system of all the organ systems was highly affected (79.10\%), followed by GIT (16.66\%) and Endocrine system (03.33\%).

The causality assessment was done by using WHO-UMC scale, Naranjo scale wasn't preferred as it is very tedious and the results at instances are misleading. As no rechallenge was done to these patients none fitted into the category of certain (Table 6).

In Tables 7 and 8 the feedback from the Psychiatric health care professionals towards the need of a clinical Pharmacist during Ward rounds is shown. The Interventions carried out by a clinical Pharmacist

\begin{tabular}{|c|c|c|}
\hline Drugs involved & Outcome & $\begin{array}{c}\text { Organ system } \\
\text { affected }\end{array}$ \\
\hline Lithium+ Olanzapine & Hand Tremor & CNS \\
\hline Lamotrigine+ Carbamazepine & Constipation & GIT \\
\hline Carbamazepine+ Asenapine & Slurring of speech & CNS \\
\hline Resperidone+ Lorazepam & Increased sedation & CNS \\
\hline Gabapentin+ CPZ & Dry mouth & CNS \\
\hline Olanzapine+ Lorazepam & $\begin{array}{c}\text { Dizziness, Drowsiness, } \\
\text { Giddiness, Slurring of } \\
\text { speech }\end{array}$ & CNS \\
\hline Lorazepam+ CPZ & Increase sedation & CNS \\
\hline Olanzapine+ divaloprex sodium & Excess sedation & CNS \\
\hline Lorazepam+ divaloprex sodium & Excess sedation & CNS \\
\hline Lorazepam+ Resperidon & Facial puffiness & Circulatory System \\
\hline Lorazepam+ Trihexyphenidyl & Facial puffiness & Circulatory System \\
\hline Trihexyphenidyl+ Resperidon & Facial puffiness & Circulatory System \\
\hline Divaloprex sodium+ diclofenac & Pedal odema & Circulatory System \\
\hline Sodium & Excess sedation, & CNS \\
\hline CPZ+ Benzyzine & Headache & CNS \\
\hline Clonazepam+ Desvenlafaxine & Drowsiness & \\
\hline
\end{tabular}

Table 5: Drug-drug Interaction.

\begin{tabular}{|c|c|}
\hline WHO Probability Scale & Percentage (\%) \\
\hline Certain & 00 \\
\hline Probable & $84.44 \%$ \\
\hline Possible & $15.55 \%$ \\
\hline
\end{tabular}

Table 6: Causality assessment of ADE as per WHO PROBABILITY SCALE. 
Citation: Khoda DA, Ganachari MS, Wadhwa T, Walli S, Parihar B, et al. (2014) Clinical Pharmacist Driven Impact towards Intensive Monitoring and Reporting of Adverse Drug Events in Psychiatric Patients. J Pharmacovigilance 2: 128. doi:10.4172/2329-6887.1000128

Page 4 of 6

\begin{tabular}{|c|c|c|c|c|}
\hline SI. No & Question & Yes & No & May be \\
\hline 1. & Was the information provided beneficial? & $06(100 \%)$ & 00 & 00 \\
\hline 2. & Will it bring any improvement towards better patient care? & $04(66.66 \%)$ & 00 & $02(33.33 \%)$ \\
\hline 3. & Will it improve the HRQOL of patient? & $05(83.33 \%)$ & 00 & $01(16.66 \%)$ \\
\hline 4. & Will it show any changes on the pocket cost of patient? & $04(66.66 \%)$ & 01 & $01(16.66 \%)$ \\
\hline 5. & Are you satisfied with the personal training on ADE reporting? & $06(100 \%)$ & 00 & 00 \\
\hline 6. & Will it help in further ADE reporting? & $06(100 \%)$ & 00 & 00 \\
\hline 7. & Do you think the presence of clinical pharmacist will help in better patient care? & $05(83.33 \%)$ & 00 & $01(16.66 \%)$ \\
\hline 8. & $\begin{array}{l}\text { Do you think this type of study should be conducted on regular basis in the } \\
\text { psychiatric wards? }\end{array}$ & $06(100 \%)$ & 00 & 00 \\
\hline
\end{tabular}

Table 7: Feedback by psychiatric health professionals.

\begin{tabular}{|c|c|c|c|}
\hline I.P number of subject & Reaction & Clinical Pharmacist approach & Management of ADE \\
\hline 0490635 & Constipation & $\begin{array}{l}\text { Psychiatrist was informed that Lamotrigine and Carbamazepine in patient } \\
\text { treatment therapy had evidence of causing constipation }\end{array}$ & Antidote suggested \\
\hline 0507054 & Hand tremor & $\begin{array}{l}\text { Evidences stated along with disease condition(AWS), lorazepam 2mg(1-1-2) } \\
\text { could also cause hand tremor }\end{array}$ & Dose reduced \\
\hline 0496783 & Hand tremor & $\begin{array}{l}\text { Evidences stated along with disease condition(substance abuse), lorazepam } \\
\qquad 2 \mathrm{mg}(1-0-2) \text { could also cause hand tremor }\end{array}$ & Dose reduced \\
\hline 0487023 & Nausea & Evidences stated Sertraline could cause nausea & No change \\
\hline 0508452 & Giddiness & Evidence stated lorazepam at a dose of $2 \mathrm{mg}(1-0-2)$ could cause giddiness & Dose reduced \\
\hline 0520180 & Increase Sedation & $\begin{array}{l}\text { Evidence states benzyzine and CPZ both can cause sedation; interaction with } \\
\text { each other caused increased sedation. }\end{array}$ & Dose reduced \\
\hline
\end{tabular}

Table 8: Intervention by Clinical Pharmacist.

\section{Management of ADE (\%)}

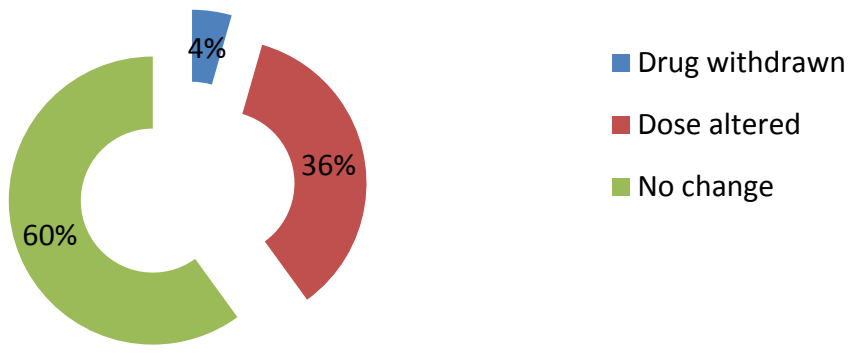

Figure 2: Management of ADE.

during ward rounds and the implementations done by the psychiatrists are shown in Table 8.

The management (Figure 2), treatment (Figure 3) and outcome (Figure 4) of the subjects with $\mathrm{ADE}$ is shown in the respective graphs and none of the ADE reported proved to be life threatening or fatal to the patients; although ADEs did increase the length of stay in the hospital. Immediate actions were taken by the treating physicians to treat the occurred event by dose modifications, supplement drug therapy, at times even drug withdrawal was considered.

\section{Discussion}

It is evident that there is a great paucity of literature in India when it comes to reporting of adverse drug reactions in psychiatry patients. This study was carried out to estimate the incidence of ADEs in the Hospital psychiatric patients. The incidence of ADEs was much higher at our setting when compared to another setting which shows an incidence rate of 9.8 per 100 residents. Data available shows that most of the adverse drug reactions are due to the well-established drugs in market rather than the newer drugs [2]. On completion of the phase 4 studies the drug is made available to the larger group of patient population. This is the period when the actual drug reactions come into picture, on a longer run.

Schizophrenia is a condition caused due to altered levels of dopamine and serotonin. Mainly atypical antipsychotics (olanzapine, resperidone) are used to treat these patients. One of the most common symptoms of schizophrenia is anxiety and most of the patients are prescribed with a benzodiazepine (lorazepam) to overcome it. In this Hospital $32.75 \%$ of all the diagnosis accounted for schizophrenia where as in another hospital setting at Kolkata patients with BPAD (27\%) were highly diagnosed in 2010 [7].

Lorazepam caused ADEs like decreased appetite, restlessness, increased sedation, headache, dry mouth and was at first position among all drugs to cause ADEs while on comparing with another study showing Olanzapine (31.82\%) to account for highest number of ADE followed by haloperidol (19.30\%) [7]. A Brazilian study carried out in 2001, suspected 219 ADRs from psychotropic drugs with antidepressants accounting for the highest group of psychotropic drugs causing ADRs [8]. 

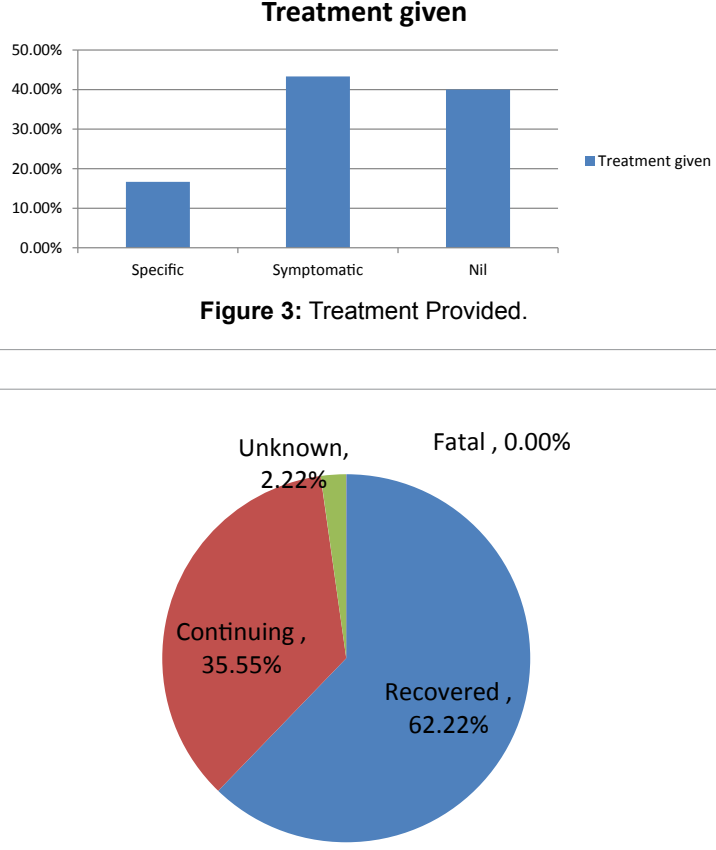

Figure 4: Outcome of ADE.

In a study carried out in geriatric psychiatry patients it was seen that majority (68.42\%) of the adverse drug reactions fitted into level 3 and 4 of Hartwig scale [9]. The scoring on Hartwig severity scale in our set up showed majority of the reactions belonged to Level 1 accounting for $65.55 \%$ followed by level 2(27.77\%) and Level 3 with (6.66\%). Majority were categorized as level 1 because for these reactions no changes were implemented. Eg- conditions like restlessness, irritability etc.

Improving the health of the patients and taking further care of their health is a growing health policy for all hospitals to run efficiently [10]. In recent years, lot of importance has been given towards observing, monitoring and reporting of adverse drug reactions worldwide. In India it was from January 2005, when the National Pharmacovigilance program was established and still our country is in its nascent stage when it comes to viewing the documented and reported ADE towards psychotropic agents [10,11]. A Bulgarian study showed that the frequency of $\mathrm{ADE}$ of individual psychotropic drug is studied less than $1 \%[12]$.

It would be biased if the drugs were only held responsible for the occurrence of the unwanted reactions; there are various other predisposing factors often left unnoticed when accounting for actual cause of event. Factors like compliance to therapy by the patients, inappropriate prescribing, socioeconomic status, co morbid disease conditions, and negligence by the patient's. Nearly 62 patients $(68.88 \%)$ were on multiple drug therapy and this too could be considered as a contributing factor towards the reaction. Failure of continuation to drug therapy by patients was seen in few cases and led to increased resistance and poor disease compliance.

The under reporting of ADEs can be attributed towards time factor, lack of knowledge, negligence, whom to contact etc. The introduction of yellow cards at the hospital nursing station can be one important tool to increase the reporting of ADEs in the respective wards. Not only the implication of the cards but along with it conducting of educational programs for the Psychiatrists, Post graduates and on duty nursing staff towards Pharmacovigilance and its aim in better patient care will certainly help in bringing out more unseen cases of ADEs and increase the evidence based practice. A study from Spain, suggests the use of Yellow Cards, availability of a Clinical Pharmacist at rounds, bringing about easier aspects to report ADEs like the fax, telephone, sms increased the reporting of adverse drug reactions [13]. There are a lot many ADEs which go unnoticed and left untreated. Medication errors are a major issue of concern these days, lot many educational programs have been carried out for the health care team but this alone would do no good, using of information technology where in the physician provides printed prescription stating all the indication of use of drugs can do some good to psychiatry patients [14]. Even the application of bar code system and unit dose dispensing can avoid administration errors and in turn help reducing the rate of ADEs.

\section{Limitations}

The limitations of the study being only those ADEs which were seen in the presence of the pharmacist were reported and documented. Since the sample size is small this data cannot be generalized.

\section{Conclusion}

The fact goes undenied, psychiatric patients are prone towards adverse events, the only good that could be done to these subjects is try avoiding and minimizing the events. This could be possible only by thorough monitoring of such cases. Patient counselling by clinical pharmacist can help the subjects and their relatives in better understanding of their drug; the outcomes of stopping or missing any doses. The imperative to minimize the occurrence of ADEs is not a sole responsibility bestowed upon the pharmacist; it would be only possible when the health care team join up hands and share the responsibility among them. The use of information technology and better communication between the health team and patients can help in a greater extent to reduce the occurrence of ADEs.

\section{Acknowledgment}

This manuscript is acknowledged towards every Health care Professional for the betterment of society and its living and no grants or funds were taken from any source or agencies and there appears no conflict of interest by any of the contributing authors.

\section{References}

1. Vilhelmsson A, Svensson T, Meeuwisse A, Carlsten A (2011) What can we learn from consumer reports on psychiatric adverse drug reactions with antidepressant medication? Experiences from reports to a consumer association. BMC Clin Pharmacol 11: 16.

2. Jain T, Bhandari A, Ram V, Parakh M, Wal P, et al. (2011) Drug interactions and adverse drug reactions in hospitalized psychiatric patients a critical element in providing safe medication use. Ger J Psychiatr: 26-34.

3. Mann K, Rothschild JM, Keohane CA, Chu JA, Bates DW (2008) Adverse drug events and medication errors in psychiatry: methodological issues regarding identification and classification. World J Biol Psychiatry 9: 24-33.

4. Pirmohamed M, Healy D, Medawar C, Holdcroft A, Ashton H, et al. (2008) Adverse psychiatric side effects of medicines: what's our responsibility? APRIL's Third Conference.

5. Sengupta G, Bhowmick S, Hazra A, Datta A, Rahaman M (2011) Adverse drug reaction monitoring in psychiatry out-patient department of an Indian teaching hospital. Indian J Pharmacol 43: 36-39.

6. Jayaram G (2008) Measuring adverse events in psychiatry. Psychiatry (Edgmont) 5: 17-19.

7. Maidment ID, Lelliott $P$, Paton C (2006) Medication errors in mental healthcare: a systematic review. Qual Saf Health Care 15: 409-413.

8. Carlini EL, Nappo SA (2003) The pharmacovigilance of psychoactive medications in Brazil. Rev Bras Psiquiatr 25: 200-205. 
Citation: Khoda DA, Ganachari MS, Wadhwa T, Walli S, Parihar B, et al. (2014) Clinical Pharmacist Driven Impact towards Intensive Monitoring and Reporting of Adverse Drug Events in Psychiatric Patients. J Pharmacovigilance 2: 128. doi:10.4172/2329-6887.1000128

9. Beard K (2005) Drug treatment as a cause of hospital admission. J R Coll Physicians Edinb 35: 35-36.

10. Shah R, Gajjar B, Desai S (2012) A profile of adverse drug reaction with risk factors among geriatric patients in a tertiary care teaching rural hospital in India. National journal of Physiology, pharmacy, pharmacology 2: 113-122.

11. Dimitrova Z, Doma A, Petkova V, Getov I, Verkkunen E (2002) Psychotropic drugs in Bulgaria-frequency and risk of adverse drug reactions. Boll Chim Farm 141: 75-79.
12. Vallano A, Cereza G, Pedròs C, Agustí A, Danés I, et al. (2005) Obstacles and solutions for spontaneous reporting of adverse drug reactions in the hospital. Br J Clin Pharmacol 60: 653-658.

13. Bates DW, Cullen DJ, Laird N, Petersen LA, Small SD, et al. (1995) Incidence of adverse drug events and potential adverse drug events. Implications for prevention. ADE Prevention Study Group. JAMA 274: 29-34.

14. Thomas M, Boggs AA, DiPaula B, Siddiqi S (2010) Adverse drug reactions in hospitalized psychiatric patients. Ann Pharmacother 44: 819-825. 